\title{
Converge or not converge: the European Union and higher education policies in the Netherlands, Belgium/Flanders and Germany
}

\author{
Vojin Rakic \\ Center for Higher Education Policy Studies (CHEPS), University of Twente, P.O. Box 217, \\ 7500 AE Enschede, Netherlands
}

\begin{abstract}
This article examines the impact of European integration on higher education policies of the Netherlands, Belgium/Flanders and Germany. The analysis of higher education policies in the three countries is part of a broader project, which focuses on a majority of E.U. member states. The selection of the three countries for this paper is not based on any methodological considerations. The question addressed is if higher education policies of member states are converging, diverging or not changing at all, and whether such developments are a consequence of the policies of the European Union (E.U.) or of other factors (e.g., the globalization of the market or of institutions imitating each other). A preliminary assessment leads to the conclusion that a number of important indications of convergence are present in national policy arrangements in the field of higher education (in particular student mobility and quality assurance, but less in the structure of higher education systems My attention will be focused on the structure of higher education systems, on quality assurance and on student and teacher mobility. These domains appear to cover most relevant issues pertaining to higher education policies in the European Union member states (funding of higher education is sometimes considered as a separate domain, but it can also be regarded as an element of the structure of higher education systems, while it is also related to the issue of quality assurance).). The European Union, however, does not have much legal authority in the policy sector in question. Thus, an explanation for converging national policies may lie elsewhere, in part in the concept of "institutional isomorphism". (C) 2001 International Association of Universities. Published by Elsevier Science Ltd. All rights reserved.
\end{abstract}

Keywords: Convergence; Higher education systems; Institutional isomorphism

\section{Terminological distinctions}

What impact does European integration have on the higher education policies of Germany, the Netherlands and Belgium/Flanders? ${ }^{1}$ To answer this question, this article

${ }^{1}$ After the federalization of Belgium in 1989, higher education policies were almost completely transferred to the regional level and the level of the language communities. The focus will be on higher education in Flanders, treating it as a part of the Belgian system before 1989 . 
will assess whether the higher education policies of these three countries were converging, diverging or unchanging? The part, clarifies relevant concepts, such as diversity, divergence and convergence. In the second, develops the hypothesis that a convergence of policies is to be expected in E.U. member states and sets out reasons for this expectation. The third develops a "general scheme" to explain convergence mechanisms. Marker events in higher education policy at the Union level are chronologically reviewed in part 4 . Corresponding events in the three member states are analyzed in part 5. Finally, concluding remarks in the context of the central issue, namely, the essential mechanism of institutional isomorphism are made.

A substantial body of literature in higher education deals with convergence/divergence (homogeneity/diversity ${ }^{2}$ ) at the level of higher education institutions and at the level of disciplines. Birnbaum (1983) distinguishes two forms of diversity: external diversity, based on differences among higher education institutions, and internal diversity - differences within higher education institutions. This article concentrates on a third form of diversity, on differences among higher education policies. The term I will use for it will be diversity policy in systems.

Changes to one form of diversity can be accompanied by changes in another form of diversity in the opposite direction. For example, divergence among higher education institutions within a higher education system can be the result of converging policies at the systems level. For instance, E.U. policies to promote diversity can lead to convergence at the systems level (the E.U. member states adopt similar policies aimed at the promotion of diversity) which may result in divergence at the institutional level of higher education within member states. Secondly, convergence among higher education institutions within a system (external convergence) may result from diverging policies at the policy systems level. For example, different policies of stipulated governments can result in higher education institutions becoming less diversified.

This complicated relationship between convergence and divergence warns us not to confuse convergence or divergence among higher education institutions (or even within a higher education institution) with the same phenomena at the systems level, i.e. with higher education policies. Thus, the present convergence or divergence is contingent upon the level of aggregation (e.g., divergence may take place at institutional level, whereas convergence may be observed at the systems level).

To clarify these distinctions, three influential perspectives on the question of diversity/ homogeneity and divergence/convergence in higher education will be examined. The first, internal perspective, is explored by Burton Clark; the second, policy system perspective, was analyzed by Guy Neave, and the third, mainly external perspective, draws on the writings of Frans van Vught. ${ }^{3}$

Clark (1996) focused on the internal perspective, which emphasized the basic unit in higher education institutions, i.e. the academic discipline. He regarded differentiation as

\footnotetext{
${ }^{2}$ I will use the terms homogeneity/diversity to denote a particular (static) state of affairs, whereas convergence/divergence and homogenization/diversification (or differentiation) will be employed to denote a particular process, i.e. a dynamics. For an extensive review of these concepts, consult Huisman (1995).

${ }^{3}$ My discussion of the three perspectives of Clark, Neave and Van Vught, does not suggest that these authors are somehow proponents of the three perspectives. They did not suggest that any one of the three is the only right or most important one.
} 
a natural process in higher education ("the creation of finely distinguished subcultures in academia is a natural process" (Clark, 1996, p. 19). $)^{4}$ Clark remarked on "balkanized authority" in higher education (Clark, 1996, p. 20) Thus:

... higher education is a differentiating society par excellence. It adjusts internally to increasing arrays of input demands and output connections by greater specialization in its production units and the programs they offer. Adapting to the changing contours of rapidly expanding and highly specialized knowledge, it creates more varied types of academic tribes.... Higher education is preeminently an internationally shaped component of modern and modernizing societies... . The dynamic of differentiation is a powerful root cause of the tendency for higher education to be a self-guiding society. Governments and other patrons will increasingly find higher education to be a contentious area highly resistant to command and control (Clark, 1996, p. 24).

Clark explains apparent convergence processes, by arguing that what we interpret as convergence is, in fact, divergence along a continuum:

Academic drift is a converging form of drift; second and third sectors of institutions converge on a first sector as they seek to emulate its ways and to gain similar power and prestige... . They only achieve 'weak emulation'. Individually the emulating institutions add to differentiation as they become variously sorted out along a continuum of degrees of difference (Clark, 1996, p. 23).

Neave (1996) concentrated on the systems level. His attention lay in higher education policies, in particular to the national and supranational policy levels. The "European dimension" has to be taken into account seriously in research on higher education policies of its member states, "even if it is not entirely clear at present how it bears upon the issue of convergence versus divergence" (Neave, 1996, p. 29).

Elsewhere, Neave believes that E.U. policies do result in convergence among national higher education policies:

There can be little doubt of the influence the European Commission is already exerting at establishment level and, no less important, as a force for convergence between systems (Neave, 1996, p. 31).

The 'European dimension' - or what is termed as 'Community level' action in the inimitable jargon of Brussels - is explicitly constructed around the ultimate aim of economic, financial and industrial integration in which convergence stands as the highway leading to this ultimate goal. These three areas of activity cannot, unless one believes in the convenient legend of the university as an ivory tower, but move higher education systems in the member states towards a similar condition (Neave, 1996, p. 38).

However, Neave was also well aware of the difficulties in assessing whether convergence or divergence are involved:

\footnotetext{
${ }^{4}$ For a more elaborate statement of Clark's position, see Clark (1983).
} 
In effect, the perception we have of a particular system and a fortiori of whether it is diverging or converging is largely a function of where we focus our attention. Like the Cheshire Cat, sometimes we see a tail, sometimes a head and sometimes just the grin (Neave, 1996, p. 28).

...homogeneity, convergence, diversity and variety are not absolutes. They are temporary and unstable conditions which always bear watching and, for that reason, will always be part of the warp and weft to our fields of enquiry (Neave, 1996, p. 39).

Van Vught's (1996) explanatory framework derived from three theoretical perspectives grounded in organizational theory: the population ecology perspective, the resource dependency perspective and the institutional isomorphism perspective (Van Vught, 1996, p. 43). He focused on the environments (primarily governments) in which higher education institutions operate, as well as on academic norms and values (i.e. academic culture):

The various empirical studies appear to underline the notions of the theoretical framework presented earlier. According to the authors of these studies, environmental pressures (especially governmental regulation) as well as the dominance of academic norms and values (especially academic conservatism) are the crucial factors that influence the processes of differentiation and dedifferentiation in higher education systems. In all cases, the empirical observations point in the direction of dedifferentiation and decreasing levels of diversity. The overall impression is that, in empirical reality, the combination of strict and uniform governmental policies and the predominance of academic norms and values leads to homogenization (Van Vught, 1996, p. 56).

All three approaches insist on change. Thus, they attempt to establish if there is convergence or divergence in the field of higher education. However, each concentrates on different levels of analysis. Clark primarily focuses on academic disciplines, i.e. on internal diversity. Neave's interest is mostly directed toward (national and supranational) policies, i.e. toward policy system diversity. Van Vught deals mostly with developments within higher education systems, i.e. with external diversity. Clark observed divergence, Neave and van Vught mostly convergence (though with reservations). Since the three approaches deal with different levels of analysis, they are not mutually exclusive. It is, possible for instance, for divergence to take place at the level of academic discipline, while convergence occurs simultaneously at the institutional level within a system and among systems. In this analysis (which focuses on the systems level), these distinctions are relevant. National policies may be influenced not only by E.U. policies, but also by higher education institutions and developments at the discipline level (effectively, academic norms and values).

Finally, convergence and divergence in our domain can apply to policy statements, policy ends, as well as to the means by which they are achieved. For instance, the acceptance of legislation does not necessarily imply its implementation. Convergence ought to be observed in such a case, however, even if it is limited to policy statements. 


\section{The hypothesis}

What are the causes of convergence or divergence? One of the dilemmas of students of convergence/divergence in the E.U. is whether an increase in similarities between member states flows from Europeanization or from a broader process of globalization. ${ }^{5}$ It is an extremely complex issue and its solution is therefore difficult. However, that it is not essential, because the effects on convergence/divergence of the processes of Europeanization and globalization are generally identical. Europeanization and globalization as processes work in the same direction. They undermine the centrality of the nation state. Olsen (1997) argued that the policies of the E.U. are large scale and heterogenous, and that few shared moral and causal beliefs exist in such policies. Such an absence of normative and cognitive integration diminishes informal, cultural coordination, and increases the relevance of market exchange and legal rules ${ }^{6}$ (Olsen, 1997, p. 170).

From the perspective of normative political theory, Olsen implies the replacement of communitarian morality (in which the community is the central unit of morality) with another form of morality, based on the centrality of market competition. Communitarian morality frequently manifests itself as national solidarity. National solidarity implies, among others, the concept that wealth ought to be redistributed along the community's boundaries, i.e. along the boundaries of the nation states, instead of the boundaries of larger units, such as the E.U. In the absence of what for nation states is a characteristic communitarian solidarity (which offsets the undesirable effects of the market through a redistribution of wealth), the principle, increasingly pronounced at the European level is competition. Competition is also one of the essential features of globalization. Hence, the effects of globalization and European integration are in that sense, similar.

The consequences for convergence/divergence are the following. Increased competition may result both in differentiation and in dedifferentiation of the entities in question. The former result comes from the relevant entities finding their "niches", whereas the latter result affects those entities that cannot adapt to the environment, failing to survive. $^{7}$ That European integration and globalization may result both in differentiation and in dedifferentiation of the policies of E.U. member states, will be more straightforward if observed from the perspective of these policies. From that perspective, E.U. member states are exposed to an increasingly homogenous environment. Homogenization is an effect of Europeanization/globalization. That all E.U. member states are exposed to increasingly similar environmental conditions leads one to predict a convergence of higher education policies, and convergence at the institutional level.

\footnotetext{
${ }^{5}$ My use of the term "broader" is not intended to suggest that Europeanization is a trend which is only part of the process of globalization. My use of the term globalization refers to a relatively recent development, related to the fall of the state-socialist bloc and to an increasingly important role of global competition and the institutions that accompany it (such as multinationals). Europeanization is a process that started earlier and can be related to the development of the European Community or even to much earlier examples of European solidarity (e.g., the role of the Crusades against the Ottoman threat)

${ }^{6}$ It should be noted, however, that the ideology of the market is a type of moral belief itself.

${ }^{7}$ For a clarification of the concepts of differentiation and dedifferentiation as its opposite, see again Huisman (1995, pp. 13-52).
} 
One may hypothesize that Europeanization and globalization will both have the same effect on policy change in the E. U. member states, and that this effect will result in policy convergence. The hypothesis is based on the proposition that Europeanization/ globalization will expose member states to an increasingly homogenous environment.

This increasingly homogenous environment sets off the impact of European integration on the policies of member states from issues of natural selection in the world of biology. ${ }^{8}$ The evolution of organisms, is not marked by convergence resulting from their increased exposure to more similar environmental conditions. Europeanization and globalization, however, do expose the policies of E.U. member states to an increasingly homogenous environment. ${ }^{9}$

Further essential difference between natural selection in the world of organizations/ institutions and in the world of biology resides in the former process involving more or less rational individuals. Biological theories of natural selection, by contrast, do not assume that selection processes take place according to a rational plan. In biology, a dynamic exists between survival strategies of specific individuals and of species. Similarly, organizations demonstrate a survival tendency, whereas individuals attempt to survive within these organizations. The difference between organisms and individuals within organizations is that the former generally do not employ rational survival mechanisms (human beings are an exception), which implies that species also do not survive on the basis of rational actions. Individuals within organizations and institutions, have recourse to survival strategies, that are more or less rational which implies that organizations do survive on the basis of rational action.

This has implications for the issue of convergence/divergence in policies (E.U. member states). Policy makers are aware of increasing European integration. They expect a slow, but steady homogenization in the European Union. Hence, they will attempt to adopt policies that will not isolate their country from others in a particular policy domain. Neave ranged this type of behavior under the rubric of "the law of anticipated results" (Neave, 1996, pp. 29-30). Its upshot is to blur differences in policies, that is, convergence.

There are also factors which inhibit convergence. A high degree of institutionalization in a policy field will predictably inhibit the process of convergence, just as internationalization will induce them. Higher education is just such a field-more institutionalized, but less internationalized than many others in the European Union. ${ }^{10}$ This does not imply, however, that policy divergence or a static situation will result. It only means

\footnotetext{
${ }^{8}$ For an understanding of the link between organizational theory and theories in the domain of biology, Hannan and Freeman (1989), Hawley (1986) and Huisman (1995) can be instructive. Consult also Pianka (1974).

${ }^{9}$ Europeanization/globalization may also result in member states perceiving the environment as increasingly homogenous. Such a perception will presumably lead to similar policy responses in the member states and thus to similar outcomes (i.e., convergence), especially if the causes of environmental homogeneity are interpreted similarly.

10 "Less internationalized" does not mean there are typically national academic disciplines. Higher education as a policy sector in the member states of the E.U. is characterized less by international dependence than other policy sectors (e.g., environmental policy).
} 
that in higher education policies processes of convergence may be less pronounced than in other policy fields. Convergence, then remains our predicted outcome.

Thus, the exposure of higher education policies of E.U. member states to increasingly homogenous environmental conditions, combined with the fact that rational policy makers will apply survival strategies for their organizations and themselves in keeping with the "law of anticipated results" (the anticipated result is an increasingly similar European environment), will lead to convergence. The hypothesis is higher education policies in the member states of the E.U. will tend toward convergence.

\section{A general scheme}

What might be the possible mechanisms of convergence In principle, convergence in national higher education policies may flow from

(a) reactions by E.U. member states to policies of European institutions (the activities of the Commission and the European Court of Justice are particularly relevant);

(b) developments at the institutional level in individual E.U. member states, as well as developments at the level of academic disciplines;

(c) mutual influence of policies upon and by individual E.U. member states.

Hence, reasons for convergence may rest on:

(a) E.U.-related coercion and an awareness of the benefits of abiding by E.U. decisions; ${ }^{11}$

(b) an insight into the benefits of accommodating to institutional changes within national higher education systems, as well as an appreciation of the benefits of accommodating to developments inside academic disciplines;

(c) imitation and member state-related coercion (i.e., one state pressing another into accepting a particular policy).

E.U.-related coercion and member state-related coercion, as well as insights into the benefits of abiding by particular E.U. decisions or of accommodating to developments at the level of higher education institutions or academic disciplines, can be regrouped as motivations guided by self-interest. Imitation may spring from rational self-interest, as well as from "self-prescription", which includes non-calculative imitation of authority and non-calculative imitation of a numerically dominant example (fashion is frequently an instance of the latter type of behavior).

\subsection{General scheme}

Amongst possible reasons for convergence of national higher education policies in E.U. member states seen from the perspective of national policy-makers ${ }^{12}$ are:

\footnotetext{
${ }^{11}$ In the latter case we deal with benefits less related to coercion.

12 Divergence, on the other hand, can be a result of an absence of coercion at the European level, but also of individual E.U. member states reacting differently to E.U. legislation.
} 


\subsubsection{Self-interest}

(1) Coercion:

(a) by E.U. institutions,

(b) by other member states.

(2) Self-interested behavior unrelated to coercion:

(a) benefits anticipated by responding to E.U. policies,

(b) benefits deriving from developments at the institutional level,

(c) benefits related to developments at the discipline level,

(d) calculative imitation of other policies. ${ }^{13}$

\subsubsection{Self-prescription}

(1) Non-calculative imitation of policies of an authority.

(2) Non-calculative imitation of numerically dominant policy examples.

The next step involves assessing whether convergence/divergence has occurred in the policies of the Netherlands, Germany and Belgium/Flanders ${ }^{14}$ and consequently, whether convergence/divergence (or neither) resulted from E.U. policies or from other factors. Let us note however that the E.U. has promulgated very little legislation on higher education. It has, however passed a variety of policy initiatives in the domain of mobility. The most relevant were the action programmes COMMETT, ERASMUS, SOCRATES and LEONARDO DA VINCI. ${ }^{15}$ Also important for processes of convergence in higher education systems and policies are the Sorbonne Declaration (1998) and the Bologna Declaration (1999), even if the two declarations were not European Union documents. The Sorbonne Declaration was an initiative taken by a number of member states as their own (France, the United Kingdom, Germany and Italy). Similarly, the Bologna Declaration was an initiative by states and some members of the E.U., not others.

\section{Developments in the Netherlands, Belgium/Flanders and Germany}

Before the 1980s, the state was the major and indispensable actor in higher education policies in the Netherlands, Flanders and Germany. Governmental authority, however, did not play the same role in the higher education systems in these countries. In the Netherlands and Belgium (until the federalization of the Belgian state in 1989), authority lay in the hands of the central government whereas in Germany, the Lander possessed the essential decision making power in higher education.

\footnotetext{
${ }^{13}$ Imitation can be based on either a rational, calculative understanding of its benefits or on motivations that cannot be reduced to rational calculation. The former type of imitation will be called "calculative imitation", the latter "non-calculative (or self-prescriptive) imitation". One interesting example of calculative imitation to which Guy Neave pointed in a conversation with me is the notion of perceived imitation as an element of the law of anticipated results.

${ }^{14}$ Again, acceptance of legislation does not necessarily imply its implementation.

${ }^{15}$ For an overview and analysis of E.U. higher education policies and initiatives, see Van Heffen, Maassen, Verhoeven, de Viilder, and de Wit (1999, pp. 165-184).
} 
Higher education in Belgium was heavily dependent on the delicate balance between the different language communities, as well as the different ideological groups. Belgian politics in general, and educational policy in particular, were influenced to a significant degree by political relationships and negotiation (Wielemans \& Vanderhoeven, 1991, p. 1). In 1959, a law was adopted splitting the education system into three networks:

- A public (state) network, the Minister of Education being the organizing authority.

- An officially subsidized network, organized by municipalities and provinces.

- A "free network", run mainly by Catholic authorities (Wielemans \& Vanderhoeven, 1991, p. 3).

Higher education in the Netherlands and Germany, were not characterized to the same degree by this complicated ideological-political balance.

All three systems were imbued with the ideals of equality and equivalence, all three faced the massification of higher education during the 1960s. In the 1980s, the three systems gradually switched from a policy of equality and equivalence to policies grounded on institutional competition and on the quality of their services. In Belgium and Germany, higher vocational schools were officially introduced in 1970 (Wielemans \& Vanderhoeven, 1991, pp. 2-3; Van de Maat, 1999, p. 17).

The problem the Netherlands faced in the 1970s, and which redirected it towards more competition in the 1980 s, turned around a high student drop-out rate, lengthy study duration, insufficient academic staff and inefficient institutional management (Goedegebuure et al., 1994, p. 190). A two-tier structure was introduced, in the late 1970 s as was retrenchment measures which closed some departments and reshuffled programs. Conditional funding for research was introduced (Boezerooy, 1999, p. 11). In 1982, university funding ceased to be enrollment driven and became based on an assessment of quality and social relevance. In place of block grants, universities had to "earn" part of their budget (Goedegebuure et al., 1994, p. 199). In 1983, the Netherlands adopted a formal quality assurance system and a "conditional funding policy" which entailed institutions obtaining more autonomy if they delivered quality education (Boezerooy, 1999, pp. 50-51). In 1983, the Dutch Ministry of Education published the White Paper "Scale Enlargement, Task-Reallocation and Concentration" (STC), which envisioned mergers and set in the sector of vocational education the emergence of multidisciplinary, medium-sized institutions with considerable autonomy. This did indeed, happen to a degree even the Ministry did not envisage (Goedegebuure et al., 1994, p. 191).

Developments in German higher education in the mid-1980s followed many Dutch trends during the first half. In 1983, the Federal Ministry of Education launched the idea of more differentiation and competition (Frackmann \& de Weert, 1993, p. 151). The new 1985 Framework Act (Rahmengesetz) endowed higher education institutions with even more autonomy than they had on the basis of its 1976 predecessor. (Frackmann $\&$ de Weert, p. 143). The planning sections of the 1976 law were abolished in 1985 (Frackmann \& de Weert, p. 143). Whilst the 1983 Act, allowed institutions to propose new programs, final authority vested with the state Ministry of Education. Final decisions concerning curricula were within the institutions (Frackmann \& de Weert, p. 143). In 1985, the German Science Council (Wissenschaftsrat) following the recommendation of the Ministry of Education decided that differences in quality and performance 
should be made transparent and that funds should be allocated competitively (Frackmann \& de Weert, p. 151), a decision which corresponded to the Dutch quality assurance system and to the Dutch idea of "conditional funding" adopted in 1983. Changes in German higher education in the mid-1980s were in line with similar developments in Holland a few years before. These changes were best seen in the idea to establish a higher education system more competitive, market-oriented, efficient, in an increase of institutional autonomy, as well as in the area of quality assurance and funding.

In Belgium as well, the relationship between government and higher education underwent modification in the mid-1980s. In 1986, the Saint-Ann austerity plan was adopted, as well as a plan to rationalize the non-university sector, both being promulgated by the Ministry of Education (Wielemans \& Vanderhoeven 1991, p. 4).

The second half of the 1980s was unblemished by major developments in higher education in any of the three countries, save one in Belgium, which went far beyond higher education. In 1989, the Belgian state was federalized and higher education policies were almost completely transferred to the regions and language communities. Research policies were somewhat less affected (Wiehemans \& Vanderhoeven, p. 2). Local boards of administration were set up in non-university institutions of higher education (Wielemans \& Vanderhoeven, p. 4). From this point our attention focuses on Flemish higher education alone.

In the 1990s, higher education systems in the Netherlands and Flanders continued to come together around a number of essential issues, though German higher education did not witness major change (Frackmann \& de Weert, 1993, p. 160).

In 1990, higher vocational (HBO) institutions in the Netherlands launched further contract research (Boezerooy, 1999, p. 19). The HOOP document of 1992 recognizing skills shortages in Europe identified in the report by the advisory Committee of the European Commission (IRDAC, 1991), took up its most important recommendations. These included an increase in graduates in science and technology, more investment in recurrent education and improvement of the productivity of education systems. This policy stance also emerged in the ministerial budget statements of 1992 and 1993. The Higher Education and Research Act of 1993 (based on the 1985 government paper HOAK) extended institutional autonomy and governmental non-intervention (IRDAC, 1991, p. 13). Institutions gained substantial freedom of course development. Now, the Minister had to prove that a new program would be detrimental to efficient course provision. Previously, the burden of proof had been on the institutions. The quality of new courses was judged ex post (Goedegebuure et al., 1994, p. 1998). The quality assessment system expanded considerably in the 1990s based both on self-evaluation and external review and audit (the Inspectorate of Higher Education, peer review) (Goedegebuure et al., 1994, p. 208). Dutch higher education was funded from three sources: directly from the Ministry (some 73\%), from the Dutch Research Council (some 5\%) and from contract research (recently estimated 15\% for Universities and $8 \%$ for HBO). Contract research funding is on the increase (Boezerooy, 1999, p. 31). Tuition fees are also required and is the same for Universities and the HBO sector (Boezerooy, 1999, p. 31). Since 1999 the specific Dutch system of place allocation is also under revision: students with 8.00 or more as their grade point average are automatically admitted to the University programs of their choice (Boezerooy, 1999, 
p. 20). Finally, debate proceeds about adopting the (Anglo-Saxon) pattern of a BA/MA degree structure (Kamerman, 1999).

In Flanders a governmental decree was issued in 1991, granting vocational education (HOBU) much larger autonomy, whilst less central regulation and more "steering from a distance" was prescribed for Universities (Beverwijk, 1999, p. 33). The 1991 decree dealt in detail with quality assurance. The Flanders Inter-University Council (V.L.I.R.) was made responsible for coordinating quality assurance, based on internal and external control (external control through peer review and without government intervention. The V.L.I.R. cooperated closely with its Netherlands counterpart (the V.S.N.U.) and used its reports as a guideline (Beverwijk, 1999, p. 45). ${ }^{16}$ The decree altered the structure of academic personnel substantially, aligning it on the Dutch or US model (assistant professor-associate professor-full professor). Changes in Flemish higher education during the 1990s reduced government involvement (including cuts in government subsidies (Wielemans, \& Vanderhoeven, 1991, p. 10)) and more competition. Leaving these general trends aside, convergence with the Dutch system took place within the sphere of quality assurance, entrance requirements, and possibly within the structure of higher education (serious discussions took place in the Netherlands about adopting the BA/MA degree structure which already existed in Flanders.

German higher education, though converging towards the Dutch and Belgian/Flemish in the 1980s, did not change substantially in the 1990s and is distinguished from the two Benelux countries by its specific federal structure and decentralized authority, its insistence of the primacy of equality and equivalence (something which in Belgium is assumed in light of its specific ideological-political balance, but is being gradually removed), the absence of tuition fees (Van de Maat, 1999, p. 42), its open access policies to Universities (at least in principle) (Frackmann \& de Weert, 1993, p. 135), as well as the absence of a national quality assessment system (Van de Maat, 1999, p. 47). Yet, the Conference of University Rectors and Presidents adopted a resolution in 1995 on the assessment of teaching (both internal and external assessment), and in 1997 consultations at Lander level and at inter-regional level produced the principle of a national quality assessment system (Van de Maat, 1999, p. 47). Further trend in the direction of convergence is the increasing significance of funding higher education by the private sector (Van de Maat, 1999, p. 40).

In conclusion, convergence in the higher education sectors of Germany, the Netherlands and Belgium/Flanders is evident during the 1980s and 1990s though in the latter period clearly less pronounced in Germany), however, the role of the European Union was minor. Specifically, the European Union adopted very little legislation that forced any of the three countries to change their higher education systems. ${ }^{17}$ E.U. higher education policies hardly had any direct impact on those of the three member states. The only exception was mobility, stimulated by the E.U. through a variety of action programs (COMMETT, ERASMUS, SOCRATES, LEONARDO DA VINCI, etc.). In

\footnotetext{
${ }^{16}$ In fact, the V.L.I.R. was an earlier form of the Flemish Rectors Conference, and had little to do with quality assurance until 1991.

${ }^{17}$ The Gravier case, however, did have an impact on Belgium, because Belgian authorities were not allowed anymore to charge differential fees to European students.
} 
terms of indirect impact, these action programs introduced changes in the structure of higher education systems (e.g., the convenience of having similar BA/MA degree structures may stimulate the appropriate institutional changes), and in the domain of quality assurance (e.g., similar quality assurance criteria among the member states will positively influence student mobility).

Convergence in the higher education policies of the Netherlands, Belgium/Flanders and Germany may certainly be explained by authorities imitating each other. Behind this imitation, however, appears to be self-interest. Governments judge what trends will dominate in Europe of the future and generally try to keep pace. In that sense, the E.U. is an integrating factor and member state authorities are generally aware that, even if not directly coerced into a particular policy by the E.U., major deviation from the dominant trend will be detrimental to their country. Significantly recent important documents in the field of higher education were initiated from bottom-up by member states: The Sorbonne Declaration and the Bologna Declaration, both aim to harmonize higher education policies in a number of essential domains. ${ }^{18}$ Again, the E.U. played the central role.

In sum, a preliminary assessment would conclude that convergence in the higher education policies of the Netherlands, Belgium/Flanders and Germany did occur in the 1980s and 1990s, but that the direct role of the E.U. in the processes involved in convergence is minimal. Indirectly however, E.U. policies had an impact. Thus, the motives dominating convergence lie in benefits to be had from E.U. policies, and in the calculative and possibly non-calculative imitation of each other's policies by member states. $^{19}$

\section{Link to theories of institutional isomorphism}

That government institutions imitate each other's policies, brings us to the literature on institutions in general, and more particularly to literature on institutional isomorphism. Two important studies are worth further attention:

(1) DiMaggio and Powell's The Iron Cage Revisited. Institutional Isomorphism and Collective Rationality in Organizational Fields (1983), takes the view that, rational actors make their institutions increasingly similar, while attempting to change them. This form of convergence rests on three isomorphic processes: coercive, mimetic and normative (DiMaggio \& Powell, 1983, p. 147). Coercive isomorphism follows from formal and informal pressures on one organization by another which is dependent upon it and by "cultural expectations in the society within which organizations function" (DiMaggio \& Powell, 1983, p. 150). Mimetic isomorphism is fed by uncertainty: "when organizational technologies are poorly understood, when goals are ambiguous, or when the environment creates symbolic uncertainty" (DiMaggio \& Powell, 1983, p. 151). Normative isomorphic change is a consequence of profes-

\footnotetext{
18 "Bottom-up initialization" does not refer initiatives by higher education institutions, but by E.U. member states.

${ }^{19}$ These three motives are classified under A2a, A2d, B1 and B2 in the "general scheme".
} 
sionalization, i.e. of "the collective struggle of members of an occupation to define the conditions and methods of their work" (DiMaggio \& Powell, 1983, p. 152). ${ }^{20}$

Two major differences emerge from the "general scheme" presented earlier and DiMaggio and Powell's theory. First, the "general scheme" deals with reasons for convergence, whereas DiMaggio and Powell posit mechanisms of convergence. Second, DiMaggio and Powell address exclusively rational mechanisms, while non-rational (or rather non-calculative, to avoid confusion with "irrational") mechanisms may also lead to certain policy outcomes, including the direction of institutional change (e.g., fashion). Thus, "calculative imitation" as presented in the general scheme can be a motivational underpinning for all three types of isomorphic processes as DiMaggio and Powell identify.

(2) Scott's Institutions and Organizations (1995): also subscribes to DiMaggio and Powell's three mechanisms of isomorphic change, but regards them as elements of three pillars of institutions as well (DiMaggio \& Powell, 1983, p. 35). He differentiates between the regulative, normative and cognitive pillars. The regulative pillar includes rule-setting, monitoring and sanctioning activities (DiMaggio \& Powell, 1983 , p. 35). The normative pillar relates to rules that introduce a prescriptive, evaluative and obligatory dimension into social life. Scott argued: "Actors conform not because it serves their individual interests, narrowly defined, but because it is expected of them; they are obliged to do so" (Scott, 1995, p. 39). The cognitive pillar emphasizes stabilizing effects of shared definitions of social reality (Scott, 1995, p. 40). ${ }^{21}$

However, the normative and cognitive pillars do not differ greatly from each other. Both pertain to a particular moral obligation, with the difference that "cognitivists" tend not to attach an absolute (or even objective) value to their morality. In that sense, the cognitive pillar can be regarded as a relativized normative pillar. In contrast to the normative and cognitive pillar, the regulative pillar does not pertain to moral obligation, but to a more coercive element in obligation. Thus, the regulative pillar stimulates compliance on the basis of self-interest, the normative and cognitive pillars do so also but on the basis of what may be called 'self-prescription'.

One of the central questions is whether or not the "behavior" of institutions is primarily rational. DiMaggio and Powell insist on the rationality of actors, whereas Scott leaves more room for self-prescriptive behavior. March and Olsen (1989) make a distinction between "aggregative theories" and "integrative theories". Aggregative theories are based on rationality and exchange, ${ }^{22}$ whereas integrative theories "commonly

\footnotetext{
20 The authors note that universities and professional training institutions are important for the development of organizational norms (DiMaggio \& Powell, 1983, p. 152). Normative isomorphism may, therefore, be an important explanatory mechanism in research on the impact of academic institutions and disciplines on national (and supranational) policy making in the field of higher education.

21 The three pillars are identified as "making up or supporting institutions" (Scott, 1995, p. 35).

${ }^{22}$ Examples of aggregative (rational choice) institutional theories include North and Thomas (1973), whose economic theory emphasizes institutions as mechanisms for lowering transaction costs, as well as theories in the field of political science which regard voters as customers (see the works of Moe, Shepsle and Weingast).
} 
presume an order based on history, obligation, and reason" (March \& Olsen, P. 118). March and Olsen follow the tradition of integrative theories: "In a broad sense, we have been urging that a perspective of politics as organized around the interactions of a collection of individual actors or events be supplemented with (or replaced by) a perspective that sees the polity as a community of rules, norms, and institutions" (March \& Olsen, p. 171). ${ }^{23}$

Mimetic processes are not always rational processes. Hence, reasons for convergence or divergence of policies are not sought exclusively in the purely calculative behavior of actors. It may be true, however, that the behavior of political actors is more guided by self-interest (and is thus more calculative) than the behavior of many other societal actors. The accuracy of this assumption, however, is not certain.

In conclusion, higher education policies in the Netherlands, Belgium/Flanders and Germany did converge in the 1980s and 1990s, particularly in the domain of mobility. In all three systems, mechanisms of quality assurance developed (though not identical ones). As for the structure of higher education, the trend of convergence is less pronounced.

The direct role of the E.U. in these processes of convergence is indirect only in the sphere of mobility. Its indirect role can be detected in other domains. For instance, increased student mobility in the E.U. has an impact on the development of similar programs or similar degree structures in member states, and on the development of comparable quality assurance mechanisms. Here, calculative imitation of each other's policy by member states stands as the dominant mechanism of institutional isomorphism. In addition to calculative imitation, it is possible that non-calculative motives fuel imitation, i.e. that policy makers in one state imitate the policies of others on the basis of moral authority or shear size, rather than on grounds of pure calculation. Thus, it is a (soft) form of coercion by the E.U. which brings about convergence in the domain of mobility (with effects on other domains), and calculative (and possibly also non-calculative) imitation of policy examples that results in convergence in quality assurance and the structure of higher education systems in the three member states.

Behind this calculative (and possibly also non-calculative) imitation of policy examples lies the "law of anticipated results": Policy makers adjust their policies to the situation they anticipate, in this case, to a slow but steady process of Europeanization. However, both Europeanization and globalization imply increasing competition. A shift toward the principles of competition is clearly visible in higher education in the Netherlands, Belgium/Flanders and Germany. Higher education institutions become more autonomous, more subjected to competition and "natural selection", while the role of the governments becomes less central. A decrease of government involvement in higher education, observed in all three states, appears to be the dominant dimension in policy convergence.

\footnotetext{
${ }^{23}$ A useful classification of institutional dynamics in the international political context can be found in March and Olsen (1998). The authors distinguish two central issues that divide students of international relations and other organized systems: the basic logic of action that determines human behavior and the issue concerning the efficiency of history. It appears possible to classify aggregative and integrative theorists as well on the basis of their approaches to these two issues.
} 
Why convergence in the higher education systems of these three countries is on the increase are the last 20 years, while absent previously has to be explained. Certainly, the policies of the E.U. contributes significantly. The economic crisis of the 1970s and 1980 s reiterated the drive of higher education toward the market. ${ }^{24}$ Since this orientation became dominant across the European Union, developments resulting from it accentuated the push toward convergence in a number of domains in member states higher education systems. Convergence is both the consequences of a massification in higher education in Western Europe, as well the outcome of the increasing place of the E.U. in higher education. This, together with the steady progress of Europeanization and globalization, tipped a number of developments in the direction of convergence during these gears. Such developments were strengthened by calculative and possibly also by non-calculative imitation of policy examples.

In conclusion, convergence is emerging in the policies of E.U. member states, appears to be confirmed to some degree in the higher education sector (at least in the three countries analyzed). Whether convergence is a product of European integration, globalization or institutional isomorphism is not particularly relevant. Europeanization and globalization, have arguably the same effect on convergence/divergence, both assist a convergence based on increased competition and "natural selection". Related to institutional isomorphism, they create an increasingly homogenous environment in which imitation mechanisms (within member state policies, and within higher education institutions) become more active. Hence, Europeanization, globalization and institutional isomorphism are related processes leading to convergence with these policy fields examined here. Neither these mechanisms nor a direct impact of E.U. policies which account for the observed changes, can be answered briefly. Despite some direct effects of E.U. policies (especially in the area of student and teacher mobility), changes in higher education policies are mainly influenced by indirect mechanisms related to European integration, of which one of the essential is based on institutional isomorphism.

\section{References}

Boezerooy, P. (1999). Higher education in the Netherlands: country report of the CHEPS higher education monitor. Enschede: CHEPS.

Birnbaum, R. (1983). Maintaining diversity in higher education. San Francisco: Jossey-Bass.

Clark, B. R. (1983). The higher education system. Berkeley and London: University of California Press.

Clark, B. R. (1996). Diversification of higher education: viability and change. In L. Meek (Ed.), The mockers and the mocked: comparative perspectives on differentiation, convergence and diversity in higher education. Oxford: Pergamon Press.

DiMaggio, P., \& Powell, W. (1983). The iron cage revisited: institutional isomorphism and collective rationality in organizational fields. American Sociological Review, 48, 147-160.

Frackmann, E., \& de Weert, E. (1993). Higher education policy in Germany. In L. Goedegebuure, F. Kaiser, P. Maassen, L. Meek, F. van Vught, \& E. de Weert (Eds.), Higher education policy: an international comparative perspective. Oxford: Pergamon Press.

\footnotetext{
${ }^{24}$ This process became even more pronounced in those countries in the E.U. where the center-right took office.
} 
Goedegebuure, L., Kaiser, F., Maassen, P., Meek, L., van Vught, F., \& de Weert E. (Eds.), (1994). Higher education policy: an international comparative perspective. Oxford: Pergamon Press.

Hannan, M., \& Freeman, J. (1989). Organizational ecology. Cambridge and London: Harvard University Press.

Hawley, A. (1986). Human ecology. Chicago and London: The University of Chicago Press.

Huisman, J. (1995). Differentiation, diversity and dependency in higher education. Utrecht: Lemma.

IRDAC. (1991). Skill shortages in Europe. Brussels: IRDAC.

Kamerman, S. (1999). Bachelor/Master gaat het maken, NRC Handelsblad of 10 September 1999.

March, J. G., \& Olsen, J. P. (1989). Rediscovering institutions: the organizational basis of politics. New York and London: The Free Press and Collier Macmillan Publishers.

March, J. G., \& Olsen, J. P. (1998). The institutional dynamics of international political orders. Oslo: Arena.

Neave, G. (1996). Homogenization, integration and convergence: The Cheshire Cats of higher education analysis. In L. Meek (Ed.), The mockers and the mocked: Comparative perspectives on differentiation, convergence and diversity in higher education. Oxford: Pergamon Press.

North, D. C., \& Thomas, R. P. (1973). The rise of the Western World: a new economic history. London: Cambridge University Press.

Olsen, J. P. (1997). European challenges to the nation state. In B. Steunenberg, \& F. van Vught (Eds.), Political institutions and public policy: perspectives on European decision making. Dordrecht, Boston and London: Kluwer Academic Publishers.

Pianka, E. R. (1974). Evolutionary ecology. New York, Evanston, San Francisco and London: Harper \& Row Publishers.

Scott, R. W. (1995). Institutions and organizations. Thousands Oaks, London and New Delhi: Sage Publications.

Van de Maat, L. (1999). Higher education in Germany: country report of the CHEPS higher education monitor. Enschede: CHEPS.

Van Heffen, O., Maassen, P., Verhoeven, J., de Vijlder, F., \& de Wit, K. (Eds.) (1999). Overheid, Hoger Onderwijs en Economie: Ontwikkelingen in Nederland en Vlaanderen. Utrecht: Lemma.

Van Vught, F. (1996). Isomorphism in higher education? Towards a theory of differentiation and diversity in higher education systems. In L. Meek (Ed.), The mockers and the mocked: comparative perspectives on differentiation, convergence and diversity in higher education. Oxford: Pergamon Press.

Wielemans, W., \& Vanderhoeven, J. L. (1991). Market impact and policy drift: Belgian higher education. In G. Neave, \& F. van Vught (Eds.), Prometheus bound: the changing relationship between government and higher education in Western Europe. Oxford: Pergamon. 